\title{
Learner engagement as social justice practice in undergraduate emergency care education: An exploration of expectations, impediments and enablers for academic success
}

\author{
N Naidoo, ${ }^{1,2}$ NDipAEC, BTech EMC, HD Ed, MPH, PhD (Forensic Med); R Matthews, ${ }^{1}$ NDipEMC, BTech EMC, PGDipHETL, MPhil (Emergency Med) \\ ${ }^{1}$ Department of Emergency Medical Sciences, Faculty of Health and Wellness Sciences, Cape Peninsula University of Technology, Cape Town, South Africa \\ ${ }^{2}$ Paramedicine, School of Health Sciences, Western Sydney University, Sydney, Australia
}

Corresponding author: N Naidoo (n.naidoo2@westernsydney.edu.au)

\begin{abstract}
Background. It is uncertain how descriptions of learner experiences and expectations can influence learner engagement in prehospital emergency care education in South Africa (SA). Improved access to higher education may imply a greater diversity of life experiences and academic needs. However, neither this diversity nor the consequent disengagement-engagement differential has been documented for the emergency care student body in SA.

Objectives. To explore the expectations of, impediments to and enablers for success in undergraduate emergency care education.

Methods. A concurrent (embedded) mixed-methods design was employed. Through a prospective online survey, 115 of 249 emergency care learners who were registered in 2014 - 2018 were sampled. Qualitative responses were thematically analysed from a process of mind mapping and dyadic contrasting of codes.

Results. Three propositions emerged: (i) the paradox of programme motivation and subject hindrance suggests that participants were intrinsically and extrinsically motivated for programme completion, but experienced hindrances at the subject level; (ii) there was a perception of insufficient academic interaction and engagement; and (iii) while there were divergent experiences and expectations, coercive contexts for premature attrition in emergency care education prevail.

Conclusions. Sacrifices made by respondents to overcome challenges were identified as a profound loss of time, money and relationships. Extrinsic factors affecting learner success included competing demands, institutional structure/processes, teaching quality and online teaching and learning. A learner-centred approach is therefore posited, given expression through learner engagement. If engagement is to become a meaningful social justice practice, then monoculture ideation in emergency care education must be challenged.
\end{abstract}

Afr J Health Professions Educ 2021;13(1):59-64. https://doi.org/10.7196/AJHPE.2021.v13i1.1223

Given the extent of socioeconomic change worldwide, students may need to approach their education at different entry levels or stages of life experience. The nature of diversity this presents requires higher education institutions (HEIs) to understand the educational aspirations, aims, resources and realities of their students. Understanding this diversity, sets the stage for a student-centred response to retention and persistence, ${ }^{[1]}$ where students remain the critical actors in their own education.

Diversity in HEIs has increased, ${ }^{[2]}$ partially owing to the widening of access to HEIs and a grass-roots demand for the realisation of constitutional rights. ${ }^{[3]}$ In a South African (SA) study on the gap between students' expectations and experience, it emerged that the intensity of such a gap can negatively affect the goal of achieving access and success among learners from diverse backgrounds. ${ }^{[4]}$ On the assumption that all learners may experience varying levels of under-preparedness at some time, the identification of educational approaches that lessen the negative impact of under-preparedness on learning ${ }^{[5]}$ is a worthwhile endeavour for all.

Notwithstanding social gains (e.g. youth solidarity in an emerging constitutional democracy), HEI disruptions and consequent 'underpreparedness' resulting from recent student protests (2015 - 2017) during the 'fees-must-fall' and 'decolonisation of curriculum' campaign, may have been seen as acceptable or unacceptable struggle opportunity-costs. On the basis of disengaged students being vulnerable, and that students affected by protest disruption are particularly vulnerable, learner engagement has a value proposition that may be promotive of social justice before, during and after any disruption of HEI activity. Understanding and responding to pervasive and entrenched protest-related issues, approaches such as neoliberalism, colonialism, toxic masculinity and heteronormativity become more probable and palpable when learners are engaged and social justice orientated.

The SA prehospital emergency care (EC) system is in transition towards professionalisation. ${ }^{[6]}$ In their 'Mitigation triad for [EC] scope of practice and professional relevance', Naidoo et al. ${ }^{[7]}$ suggest the consideration of public, practitioner and patient interests. However, practitioner status is contingent upon student enrolment, making it appropriate to document the expectations and experiences of EC learners, as they may be affected by diversity, issues of access and academic epistemology. The programme design process includes the consideration of who the learner is ${ }^{[8]}$ However, an implementation bias towards who the learner will be may prevail. The aim of this article is to explore learner expectations of, impediments to and enablers for success in undergraduate EC education at an SA university. 'Access and success cannot be achieved without understanding learners' university expectations and experiences, as these are critical factors that are integrated with retention and success. ${ }^{[4]}$ 
This article explores the diversity of characteristics and self-appraised academic needs of undergraduate EC learners. The characteristics of EC learners have not been explicitly described in SA, posing challenges for student selection, curriculum design, teaching, learning and assessment, as it is unclear what EC learners' needs and preferences are. The research questions are therefore:

- What are the expectations and experiences of past and present learners of the EC programme?

- What are their self-reported enablers of and impediments to success with regard to successful completion of the degree?

In a progressive educational dispensation, where learner objectification is counter-productive to social transformation, a standardised programme cannot imply standardised learners/learning, whatever the extent of exclusivity. As graduates conform to the same practice standards in clinical scope, the inherent risk for educators is to impose inflexible pedagogy in pursuit of a singular practitioner identity. However, monoculture ideation in a so-called rainbow nation ${ }^{[9]}$ is indeed paradoxical and prejudicial. Furthermore, given that lecturers' experiences and approaches are not standardised and that typologies of knowledge require diversity in pedagogic practice, the promotion of a monoculture of practice by EC educators (through narrow selection, un-evidenced yet stoic standard setting, inflexible programmes and assessments, and singular approaches to delivery) may contribute to the 'thingification' of human beings. ${ }^{[10]}$ New students should not be forced to adopt the teaching culture of the organisation. ${ }^{[11]}$ To avoid an assimilationist approach (fostered by teacher centredness), a learner-centred approach is posited, which gives expression to critical pedagogy through academic interaction and learner engagement.

\section{Methods}

In the context of state or institutional interest in improved success, previous interviews with knowledge brokers at six SA universities $(2012-2016)^{[12]}$ led to the development of taxonomy of social justice practices. The taxonomy included 'epistemological access; values-oriented curriculum; critical pedagogies and professionalism; learner engagement and belonging; critical enquiry and communities of practice; ethical leadership and strategic embedding of practice. ${ }^{[12]}$ In this study, we take learner engagement to denote the quality of effort that students devote to educationally purposeful activities that directly contribute to the desired outcomes. ${ }^{[13]}$ In so doing, it may promote a sense of belonging and mitigate the risk of alienation, particularly inherent in undergraduate education.

A concurrent (embedded) mixed-methods (QUAL + QUAN) design, through a critical pragmatist lens, ${ }^{[14,15]}$ was employed to provide descriptions of the EC learner demographic, related experience and programme expectations. Lamkin and Saleh ${ }^{[16]}$ in the Encyclopedia of Curriculum Studies, hold that for critical pragmatists, the curriculum is the vehicle to bring about the desired social changes for the advancement of society. The terms 'student' and 'learner' are used interchangeably on the assumption of risk of polarisation associated with their philosophical inferences, such as the didactic-dialectic denotation of the former or the neoliberal connotation of the latter.

\section{Ethical approval}

Ethical clearance for the study was granted by the Fundani Centre for Higher Education Development, Cape Peninsula University of Technology
(CPUT) (ref. no. 017/18). The entire population of EC students had an opportunity to self-administer the electronic questionnaire at their convenience, with unfair exclusion obviated by the use of the existing learner management system. There was a possibility of non-response bias if students who responded differed from those who did not respond in terms of their characteristics and opinions. Non-response is an inevitable feature of ethical survey research, in which invited participants exercise autonomy by being free to decline the invitation to participate. Informed consent and voluntary participation prevailed. Responses were anonymised and researchers were aware of the risk of group harm to the extent that the programme and departmental heads were requested to independently appraise manuscripts for risk of harm.

The questionnaire contained open-ended, closed-ended and Likert scale questions that explored demographic characteristics, personal circumstances and educational preferences. Demographic, registration and learner progression data were obtained from the Higher Education Management Information System (HEMIS). All registered learners in the EC degree programme at one of four SA HEI during 2014 - 2018 were purposely sampled, including recent graduates and early/premature cases of attrition. The early-attrition group included students who were academically excluded (involuntarily) on the basis of repeated failure to complete, as well as those who self-deregistered (considered voluntary, although coercive contexts may have underpinned the decision). This study was aimed at providing direct, primary evidence of student diversity in terms of age groups, self-identified ethnicity, cultural affiliation, social background, prior educational experience, academic potential and university expectations. These elements, among others, are thought to be indicative of student diversity, ${ }^{[4,17]}$ and prominent findings are reported here.

Using Google Forms, the link was distributed to 167 registered learners: 19 most recent graduates and 63 former learners (of the early-attrition group); the eligible population was 249 . We received 115 voluntary responses from current students/graduates (12 graduates plus 103 respondents with learner registration during the reporting period; response rate $61.8 \%$ ) and 11 responses from the early-attrition group (response rate 17.4\%). Overall, the response rate was $50.6 \%$. Quantitative and qualitative responses were exported to a Microsoft Excel (Microsoft Corp., USA) spreadsheet with unique coding and grouped into an early-attrition sub-group and a group consisting of current learners/graduates. Quantitative data were analysed using R statistical software. ${ }^{[18]}$ Qualitative responses were categorised using FreeMind 0.1 open-source mind-mapping software. Thematic analysis, using a qualitative description approach, ${ }^{[19]}$ was aided by dyadic contrasting of the attrition and non-attrition groups and of merged and emergent propositions. The dyadic technique of congruity achieves consonance by excluding, defining and contrasting one part of the dissonant dichotomy with the other. ${ }^{[20]}$

\section{Results}

In the interest of describing diversity in this study sample, demographic, registration and learner progression HEMIS data proved useful. The mean ages at first registration for the population of interest and of the sample were 22.66 years and 25.17 years, respectively. The sample was representative of the population in terms of age, self-reported race and gender. Language diversity among respondents included English ( $n=53 ; 46.1 \%)$, Afrikaans $(n=31 ; 27 \%)$ and isiXhosa ( $n=22 ; 19.1 \%)$. Setswana, isiZulu, Sepedi, Shona and siSwati totalled $8.2 \%$. Notwithstanding the marital status (only $10(8.7 \%)$ 
students were married), 14 (12.2\%) were the primary caregivers for children and $21(18.3 \%)$ supported other dependents. Noteworthy too is that $16.5 \%$ $(n=19)$ indicated that they were breadwinners.

Three propositions emerged (Table 1): (i) the paradox of programme motivation and subject hindrance suggests that participants were intrinsically and extrinsically motivated for programme completion, but challenges at the subject level created cognitive dissonance; (ii) there was a perception of insufficient academic interaction and engagement (not necessarily from the early-attrition group); (iii) there were divergent (majority positive and minority negative) experiences and (met/unmet) expectations, but coercive contexts for premature attrition in EC prevail.

\section{Theme 1: The paradox of programme motivation and subject hindrance}

Motivation for the programme manifested in self-reported achievement expectations (sub-theme 1.1). Most respondents $(n=88 ; 76.5 \%)$ cited practitioner competency and proficiency as an achievement expectation, as practitioner eligibility is a prerequisite for employability. The value proposition of the programme included professional status, while the enabling of further study/knowledge was a self-achievement goal. Professional standing is valued in a context where EC education is in transition from a short-course system to one that is aligned to a national qualifications framework. Most $(n=76$; 66.1\%) respondents did not start with the programme immediately after high school and, of those, many had some healthcare and non-healthcare-related work experience. Some participants had other credentials and/or professional registration.

Qualification attainment was a proximal goal for most participants and a small minority $(n=4)$ cited resilience and agency as academic endpoints. A dichotomy of academic and non-academic challenges emerged. The former involved a heavy workload and competing interests $(n=26)$, poor time management $(n=25)$, insufficient support or poor resources $(n=15)$. The majority of non-academic challenges were financial constraints $(n=35)$, poor time management $(n=12)$ and travel time/distance $(n=10)$. Medical rescue was the only subject considered to be both an academic $(n=7)$ and non-academic barrier to success (sub-theme 1.2.) in terms of unplanned expenses. One participant's view was:

'I expected [the] BEMC [Bachelor of emergency medical care] course to be purely medical and I believe the rescue aspect of the course is a complete waste of resources and money. It is the most expensive, yet after

\section{Table 1. Themes and sub-themes}

\begin{tabular}{|c|c|}
\hline Theme & Sub-theme \\
\hline $\begin{array}{l}\text { Theme 1: The paradox of } \\
\text { programme motivation and } \\
\text { subject hindrance }\end{array}$ & $\begin{array}{l}\text { 1.1: Learner motivation for the } \\
\text { programme } \\
\text { 1.2: Medical rescue is considered as an } \\
\text { academic and non-academic challenge } \\
\text { for the attrition sub-group }\end{array}$ \\
\hline $\begin{array}{l}\text { Theme } 2 \text { : The perception of } \\
\text { insufficient academic interaction } \\
\text { and engagement }\end{array}$ & $\begin{array}{l}\text { 2.1: Academic interaction, challenges } \\
\text { and support } \\
\text { 2.2: Academic interaction and } \\
\text { engagement are considered academic } \\
\text { and non-academic challenges }\end{array}$ \\
\hline $\begin{array}{l}\text { Theme } 3 \text { : Divergent experiences } \\
\text { and expectations, and coercive } \\
\text { contexts for premature attrition }\end{array}$ & $\begin{array}{l}\text { 3.1: Lack of support measures } \\
\text { 3.2: Experiences and expectations were } \\
\text { diverse }\end{array}$ \\
\hline
\end{tabular}

completion of the course we are all registered as ECPs [emergency care practitioners] not rescue personnel. In future the university can at least consider making the rescue modules optional for those who are keen.'

Notwithstanding all students undergoing exposure to many compulsory rescue applications, spanning the built, wilderness and aquatic environments, medical rescue, as a subject, was portrayed by a minority as a 'futile' endeavour.

\section{Theme 2: The perception of insufficient academic interaction and engagement}

Academic interaction (sub-theme 2.1) may be deficient to the extent that learner autonomy is sacrificed and the threshold/tolerance for enduring 'suffering' is increased. Academic interaction and engagement were considered a non-academic and academic challenge by students and graduates. Incoherent/poor academic planning/interactions were seen as challenges to study completion. Staff-learner and learner-learner interactions were regarded as inadequate for addressing the risk of marginalisation of learners, and in the extreme, perceived as harmful.

Academic challenges (sub-theme 2.1) included study load (most commonly), capacity and perception of content relevance. However, load is relative to competing interests and/or poor time management. Insufficiency of resources or lack of support compounds workload dilemmas. An indication of no academic challenge by a few participants may reflect insufficient experience or a need that has been met. Infrequent findings in relation to academic challenges included the medical rescue burden $(n=7)$, financial constraints $(n=6)$, poor internet access at their place of residence $(n=40 ; 34.8 \%)$ and experiences of racism $(n=2)$ (without qualifying who the alleged perpetrators were). The proposition that emerged is that academic interaction may serve as an intervention toward programme completion. Participants cited that support structures or measures (as academic interactions) were needed for study completion. Lack of financial and family support completed the majority response to academic challenges (sub-themes 2.1, 2.2).

The proposition that emerged is that academic challenges for the attrition group included the promotion/interconnection of resilience, agency and identity (sub-theme 2.2). Respondents held the belief that psychological and emotional wellness were mutually exclusive (which may serve to undermine coping strategies). Moreover, current academic interactions were seen as inadequate to address learner marginalisation. Expectations were met or exceeded for 75 participants. While the majority of learners applied resilience to attain success, a small minority considered the programme insurmountable by design.

\section{Theme 3: Divergent experiences and expectations, and coercive contexts for premature attrition}

Response analysis of the early-attrition group indicated a perceived lack of support/intervention measures that created a coercive context for premature departure (sub-theme 3.1). The presence of divergent (positive/ negative) experiences, in the same programme, among the attrition participants suggests that neither is protective of premature programme exit or retention. Some respondents were ambivalent about programme challenges or 'enjoyment'. A minority of early-attrition respondents were either ambivalent or demonstrated a denial of responsibility and a desire for conditional readmission. 
There were diverse and divergent experiences/expectations (sub-theme 3.2). The majority perspective suggested that expectations had been met or exceeded. Participant experiences indicated that the programme was acceptable, enjoyable or unacceptably challenging. The lack of enablers by some respondents may suggest the presence of learnt hopelessness. Expectations included met expectations, maligned expectations or exceeded expectations, as demonstrated below:

'This course was not what I expected at all. In the sense that how it was advertised. The politics, power struggles, lecturer-learner relations, administration, expectations etc. Even [if] I knew the truth I still would have studied this degree, [it's] just the advertisement does not wholly describe this course truthfully.

'The answer to the latter is no. I have become cynical about the health system and specifically EMS as I believe it is not curative or of a problemsolving nature. It has changed me as a person and I struggle to relate to normal humans. My spirituality and sense of [humour] have been affected in a way that is not relatively optimal to who and what I would like to be. My experiences thus far have included highs and lows. My perspective on life has changed, but ironically, it has been skewed away from a pro-life persuasion. Issues with colleagues and academics and finances are a given and are not worth mentioning.

'The medical aspects yes, but not the rescue component of the course. The course is indeed similar to Medicine and it has met my expectations. Learning new skills and acquiring new medical knowledge every year, has always been my best experience. [T] his equips and empowers me as person ... I do see myself continuing and [graduating] despite my financial situation. The only thing $[\mathrm{I}]$ am worried about is the rescue component of this course because it does not quite equip and empower me in the same manner as the medical component of this course.

'Yes, the course has exceeded my expectations with regard to depth of content, the expectations on us as future practitioners, as well as the phenomenal opportunities afforded us during Clinical Practice. Rescue (all its components) has been both a surprising delight as well as an incredibly frustrating challenge. It has most certainly been worthwhile, and I fully intend to complete the degree.'

The sacrifices of the early-attrition group were motivated by the pursuit of personal wellness and family needs, sometimes presented as reciprocal sacrifices. For 56 (48.7\%) respondents, they were the first member of their family to access higher education, which nuances the reciprocal obligations. The most frequent non-academic challenge was reported to be of a financial nature. Financial constraints were self-identified as 'causal' of the premature departure and non-academic challenges (worsened by competing financial demands and work responsibilities). Not surprisingly, a reported $48.7 \%$ of respondents $(n=56)$ had work commitments while studying, while $57.4 \%$ ( $n=66)$ of participants had their living costs funded by family or bursaries, and $33.9 \%(n=39)$ were self-funded, $10(8.7 \%)$ were unable to cover their living costs. Some $(n=14)$ respondents reported that there were no academic challenges or were ambivalent. The second most frequent non-academic challenge was time management $(n=25)$ and related to procrastination and work burden. Additionally, long distances and unreliable public transport re-affirmed the education-as-struggle perspective. Furthermore, physical fitness was associated with sacrifices in terms of time and effort. The sacrifices can be understood against the finding that $39.1 \%(n=45)$ did not spend any time on hobbies or sport activities. A further $38.3 \%$ of respondents spent $<5$ hours per week on hobbies or sports. Most support measures that were required related to the need for academic interaction. Academic, personal or emotional factors had an interacting and compounding (rather than mediating) dynamic. The desired enabler for success among the earlyattrition group was considered to be staff-learner interaction. The majority view among the attrition group was that health and wellbeing needs were confounders to academic success.

\section{Discussion}

\section{Theme 1: The paradox of programme motivation and subject hindrance}

The findings reaffirm that factors related to learner engagement/ disengagement are indeed multifactorial. ${ }^{[21]}$ Upon entry to higher education, there is a motivational shift. HEIs require a greater level of intrinsic motivation (encouraged by a feeling that success is related to one's own effort), as much of the time is self-organised and much of the work is done without overt reward. ${ }^{[22]}$ The perceived futility of rescue, albeit a minority finding, may imply a disproportionate success-to-effort ratio. Many of the other potential attrition factors, such as poverty, were initiated long before entering the HEI and are not disputed in the literature. These deep-rooted factors include: academic under-preparedness, low commitment to persist, academic boredom, difficulties managing the transition to university, uncertainties about long-term goals, irrelevance of the university curriculum, social isolation, mismatch between student expectation and early experiences and finance. ${ }^{[22]}$ The study findings centred on the latter four.

Zepke and Leach ${ }^{[23]}$ synthesised 93 studies from 10 countries to develop a learner-engagement conceptual frame that consists of four perspectives: learner motivation; transactions between teachers and learners; institutional support; and engagement for active citizenship. This frame provides contextual resonance with our findings. It proposes learner engagement opportunities, ${ }^{[23]}$ all of which had direct and indirect expression in the study responses. Such learner opportunities include enhancing self-belief; enabling autonomous work; enjoying learning relationships with others; and feeling confident regarding ability. For teachers, opportunities include the recognition of their centrality to engagement; the creation of active/collaborative learning; and the fostering of learning relationships. Teachers can also create challenging/ enriching educational experiences for learners that extend their academic abilities. They can ensure that institutional cultures are welcoming to learners from diverse backgrounds; promote investment in a variety of support services; adapt to changing expectations; enable active citizenship; and enable social and cultural capital. The abovementioned opportunities summarise the value proposition for learner engagement.

\section{Theme 2: The perception of insufficient academic interaction and engagement}

Notwithstanding the large majority of this study sample describing the programme as worthwhile, partial control over learning processes may develop confidence and commitment to become learning agents (that is requisite of learner engagement). Another requirement for engagement is to cultivate intrinsic motivation, which fosters self-determination. 'Findings acknowledge that active learning in groups, peer relationships, and social skills are important in engaging learners. ${ }^{[23]}$ When learners are reflecting, questioning, conjecturing, evaluating and making connections between ideas, they are engaged. ${ }^{[23]}$ However, to become engaged, learners must first 
feel accepted and affirmed, and have a sense of belonging at an institution. Some group activities, such as group work and peer assessment, however, are not benign. In an SA case study of racial and gender problematics, a 'growing measure of discontent with the process of assessing peer contributions to group tasks emerged, including actual and perceived racial and gender stereotyping, and related rejection-sensitivity. ${ }^{[24]}$ Nonetheless, some innovations to improve learner engagement include the adoption of teaching roles, such as peer assessment/tutoring/mentoring. ${ }^{[25]}$ There are many approaches to dealing with aberrant behaviour that include political incorrectness or disengagement. ${ }^{[2]}$ Support services are perceived as part of the institutional culture, and learners are likely to engage when the culture values and supports their efforts to learn. Early attrition may arise from the institution's behaviour or a lack of congruence between individual students and institutional structures, personnel and procedures. ${ }^{[2]}$ The focus on the student experience is a strategy to value subjectivity. The inherent risk of student-institution value malalignment, is that the pursuit of knowledge is undermined. ${ }^{[27]}$ We do not imply the stigmatisation of non-traditional learners by differing approaches, but rather that learners are sufficiently motivated to attend university, prepare before attending and participate in class. We therefore posit that a learner-engagement orientation is desired to promote learner success.

\section{Theme 3: Divergent experiences and expectations, and coercive contexts for premature attrition}

There is a need to enable learners to develop their social and cultural capital. This kind of capital, however, derives from a sense of belonging. What is needed is a democratic critical conception of engagement as participatory and dialectic, leading beyond the more proximal academic success to success as an active citizen. Transformative learning effects of university courses may be seen in the integration of academic learning with practical experience, as is the case in EC. The student can act as a catalyst for this emancipatory perspective, promote 'transformative and sustainable learning experiences for all involved, not just the student, and contribute meaningfully to civil society - and are particularly pertinent to placements with organisations working for social change. ${ }^{\text {[28] }}$ The learning-throughparticipation approach ${ }^{[29]}$ refers to the experiential learning contexts, where EC learners practise within an EC organisation. Such civil society, public or private placements are located at the grass-roots level of communities and provide for a contextualisation of skills, knowledge and attitudes within sociopolitical realities and economic inequity, among other social determinants of health. ${ }^{[30]}$

The roots of the non-academic challenges appear to lie in the absence of privilege. In the systematic synthesis of 32 papers, '... student disengagement was conceptualised as a combination of behavioural, emotional and cognitive domains influenced by intrinsic (psychological factors, low motivation, inadequate preparation for higher education, and unmet or unrealistic expectations) or extrinsic (competing demands, institutional structure and processes, teaching quality and online teaching and learning) factors. ${ }^{[21]}$ This study emphasised such extrinsic factors: sacrifices made by respondents to overcome challenges include loss of time, money and relationships (the latter two being dominant). However, sacrifices were counterbalanced by coping mechanisms (in the form of coping-orientated sacrifices). Statements referring to the programme experience, such as '... It has changed me as a person and I struggle to relate to normal humans ..., make compelling argument for institutions to facilitate student skills to foster healthy and supportive relationships and to cope with any inevitable loss of relationships that inevitably invokes a sense of loss and bereavement.

As student roles are changing, students, in this study and elsewhere, face a multitude of social and personal issues that intrude into the educational setting and influence persistence and retention. ${ }^{[1]}$ The undertaking of paid work was found to contribute, rather counter-productively, to university attrition in the UK. ${ }^{[22]}$ The financial challenge extends beyond the cost of study to the preceding state of poverty from which students come, lack of financial support from/for family and insufficient income (if any) during the study period. Regarding the behavioural economics of attrition in education, factors that are negatively related to student success include a full/part-time off-campus job, hours spent watching television and hours spent commuting to campus. ${ }^{[31]}$

\section{Study limitations}

The study did not measure the competence of educators, their awareness of diversity, and their sensitivity to learner differences, and how they make use of these demographic differences in teaching and learning. ${ }^{[1]}$ Future research into a customer focus among this population should ascertain the participants' learning styles ${ }^{[32]}$ and the programme readiness to satisfy these. In the final analysis, the duty to provide meaningful educative opportunity is overwhelmingly in the hands of the educator, ${ }^{[26]}$ but the learning potential depends on the extent of learner engagement, ${ }^{[33]}$ which is limited somewhat by the abovementioned factors. Both educator and learner concepts of current and future professional identity may be given expression through these educative opportunities.

\section{Conclusion}

The study makes a knowledge contribution to learner-engagement needs in EC education. It provides useful baseline data on experiences/expectations for intervention development. Learner engagement has the potential to provide a deliberate reflective space in which they engage with their unpleasant and pleasant experiences. Through learner engagement, the promotion of voice for marginalised groups is upheld. The main contribution is a point of reflection for academics/programme designers and support for learner engagement as a social justice practice. The implications for further research include value mechanisms for subjectivity.

Finally, EC education should demonstrate a deliberate intention to promote resilience, support recovery and enable identity creation by the self. It should apply learner engagement as a theory and method of academic interaction that links curriculum to assessment and fosters coherence, promotes agency and redresses learnt helplessness. Learner engagement simultaneously redefines the role of lecturer and learner and will likely promote a shared responsibility for academic success. A reduction in negative experiences and coercive contexts and promotion of positive experiences may mitigate early attrition. Furthermore, mentoring, tutoring and constructive alignment within and between subjects are supported. Student sacrifices should be acknowledged by educators, who should work painstakingly to mitigate the profound learner losses of time, money or relationships.

\section{Declaration. None.}

Acknowledgements. Roxanne Maritz (BSc Life Sciences, BEMC, MEMC) is acknowledged for her contribution to data handling. 
Author contributions. NN and RM conceptualised the study, developed the data collection instrument and conducted the analysis. NN led the initial manuscript draft. NN and RM approved the final manuscript.

Funding. This work was supported by the Fundani Centre for Higher Education Development, CPUT, through the Research and Innovation Fund for Teaching and Learning (RIFTAL).

Conflicts of interest. None.

1. Dumbrigue C, Moxley D, Najor-Durack A. Keeping Students in Higher Education: Successful Strategies and Practices for Retention. Abingdon-on-Thames: Taylor and Francis Group, 2001:1-8. https://doi.org/10.4324/9780203062401 . Council on Higher Education. Vital Stats: Public Higher Education, 2016. Pretoria: CHE, 2018.

3. South African History. Student protests in a democratic South Africa. 2019. https://www.sahistory.org.za/article student-protests-democratic-south-africa (accessed 1 April 2019)

4. Pather S, Dorasamy N. The mismatch between first-year students' expectations and experience alongside university access and success: A South African university case study. J Student Affairs Africa 2018;6(1):49-64. https://do. org/10.24085/jsaa.v6i1.3065

5. Brüssow SM, Wilkinson AC. Engaged learning: A pathway to better teaching. S Afr J High Educ 2010;4(3):374-391. https://doi.org/10.4314/sajhe.v24i3.63444

6. Sobuwa S, Christopher LD. Emergency care education in South Africa: Past, present and future. Australas 6. Sobuwa S, Christopher LD. Emergency care educat

7. Naidoo N, Zalgaonker M, Christopher LD. Pre-hospital phlebotomy and point of care testing: Relevance and implications for professional emergency care practice. Med Technol J S Afr 2013;27(2):33. https://doi org/10.10520/EJC15043

8. Kern DE. Overview: A six step approach to curriculum development. In: Thomas PA, Kern DE, Hughs MT Chen BY, eds. Curriculum Development for Medical Education. A Six Step Approach. Baltimore: Johns Hopkin University Press, 2016:7.

9. George D. Let us revisit the idea of a rainbow nation. News24, 25 March 2018. https://www.news24.com/ Columnists/GuestColumn/let-us-revisit-the-idea-of-a-rainbow-nation-20180323 (accessed 2 April 2019).

10. Martin B. Ethical Marxism: The Categorical Imperative of Liberation. Illinois: Open Court Publishing, 2008:423. 11. Meier C, Hartell C. Handling cultural diversity in education in South Africa. SA-eDUC J 2009;6(2):180-192.

12. Wisker G, Masika R. Creating a positive environment for widening participation: A taxonomy for socially jus higher education policy and practice. High Educ Rev 2017;49(2):56-84.

13. Hu S, Kuh GD. Being (dis) engaged in educationally purposeful activities: The influences of student and 3. Hu S, Kuh GD. Being (dis) engaged in educationally purposeful activities: The influences of studen
institutional characteristics. Res High Educ 2002;43(5):555-575. https://doi.org/10.1023/A:1020114231387

14. Onwuegbuzie AJ, Collins KM. A typology of mixed methods sampling designs in social science research. Qual Rep 2007;12(2):281-316.
Qual
15. Denzin NK, Lincoln YS, eds. SAGE Handbook of Qualitative Research. 5th ed. Thousand Oaks, CA: SAGE, 2018 16. Lamkin ML, Saleh A. Critical pragmatism. In: Kridel C, ed. Encyclopedia of Curriculum Studies. Thousan Oaks, CA: SAGE, 2010

17. Leach L. Exploring discipline differences in student engagement in one institution. High Educ Res Develop 2010;35(4):772-786

8. R Core Team. R: A language and environment for statistical computing. 2018. https://www.R-project.or (accessed 25 March 2019).

19. Sandelowski M. What's in a name? Qualitative description revisited. Res Nurs Health 2010;33:77-84. https://do org/10.1002/nur.20362

20. Shoham S. Society and the Absurd: A Sociology of Conflictual Encounters. Brighton: Sussex Academic Press, 2006

21. Chipchase L, Davidson M, Blackstock F, et al. Conceptualising and measuring student disengagement in higher education: A synthesis of the literature. Int J High Educ 2017;6(2):31-42. https://doi.org/10.5430/ijhe.v6n2p31

22. Cook T, Rushton BS. How to Recruit and Retain Higher Education Students: A Handbook of Good Practice. Abingdon-on-Thames: Taylor and Francis Group, 2010.

23. Zepke N, Leach L. Improving student engagement: Ten proposals for action. Active Learn High Educ 2010;11(3):167-177. https://doi.org/10.1177/1469787410379680

24. Thondhlana G, Belluigi DZ. Students' reception of peer assessment of group-work contributions: Problematics in terms of race and gender emerging from a South African case study. Assess Eval High Educ 2017;42(7):1118-113

5. Duran FB. Considering the role of tutoring in student engagement: Reflections from a South African university. J Student Affairs Africa 2017;5(2):1-15. https://doi.org/10.24085/jsaa.v5i2.2699 (accessed 30 March 2019).

26. McCrorie P. Teaching and leading small groups. In: Swanwick T, ed. Understanding Medical Education: Evidence, Theory and Practice. 2nd ed. Oxford: John Wiley, 2014:123-137.

27. Mieschbuehle R. Beyond 'student experience'. In: Hayes D, ed. Beyond McDonaldization: Visions of Higher Education. Abingdon-on-Thames: Taylor and Francis Group, 2017.

28. Sakinofsky P, Amigo M, Janks A. Green sprouts: Transformative learning in learning through participation (LTP). Educ Res Soc Change 2018;7(2):132-145. https://doi.org/10.17159/2221-4070/2018/v7i2a9

29. Mackaway JA, Winchester-Seeto T, Coulson D, et al. Practical and pedagogical aspects of learning through participation: The LTP assessment design framework. J Univ Teach Learn Pract 2011;8(3).

30. Commission on Social Determinants of Health. Closing the Gap in a Generation: Health Equity Through Action on the Social Determinants of Health. Geneva: World Health Organization, 2008.

31. Shireman RM, Price JM. Prepare for class, attend, and participate! Incentives and student success in college. In: Castleman BL, Schwartz S, Baum S. Decision Making for Student Success: Behavioral Insights to Improve College Access and Persistence. Abingdon-on-Thames: Taylor and Francis Group, 2015.

32. Vonderembse MA. Crisis in Higher Education: A Customer-Focused, Resource Management Resolution. Abingdon-on-Thames: Taylor and Francis Group, 2018

33. Ivala E, Joseph K. Student levels of engagement in learning: A case study of Cape Peninsula University of Technology (CPUT). Perspect Educ 2013;31(2):123-134

Accepted 27 May 2020 